\title{
Multicenter study of the COPD-6 screening device: feasible for early detection of chronic obstructive pulmonary disease in primary care?
}

This article was published in the following Dove Press journal:

International Journal of COPD

4 August 2017

Number of times this article has been viewed

\author{
Peter Kjeldgaard' \\ Jesper Lykkegaard ${ }^{2}$ \\ Heidi Spillemose ${ }^{3}$ \\ Charlotte Suppli Ulrik ${ }^{1,4}$ \\ 'Department of Respiratory Medicine, \\ Hvidovre Hospital, Hvidovre, \\ ${ }^{2}$ Research Unit of General Practice, \\ University of Southern Denmark, \\ Odense, ${ }^{3}$ General Practice Aarup \\ Lægerne, Aarup, ${ }^{4}$ Institute of Clinical \\ Medicine, University of Copenhagen, \\ Copenhagen, Denmark
}

Background and aim: Early detection of COPD may reduce the future burden of the disease. We aimed to investigate whether prescreening with a COPD-6 screening device (measuring $\mathrm{FEV}_{1}$ and $\mathrm{FEV}_{6}$ ) facilitates early detection of COPD in primary care.

Methods: In primary care, individuals at high risk of COPD (ie, age $\geq 35$ years, relevant exposure, and at least one respiratory symptom) and no previous diagnosis of obstructive lung disease were examined with a COPD-6 screening device. In prioritized order, the criteria for proceeding to confirmatory spirometry were $\mathrm{FEV}_{1} / \mathrm{FEV}_{6}<0.7, \mathrm{FEV}_{1}<80 \%$ pred, or clinical suspicion of COPD regardless of test result (medical doctor's [MD] decision). Based on spirometry, including bronchodilator (BD) reversibility test, individuals were classified as COPD (post-BD FEV $\left.{ }_{1} / \mathrm{FVC}<0.70\right)$, asthma $\left(\Delta \mathrm{FEV}_{1} \geq 0.50 \mathrm{~L}\right)$, or no obstructive lung disease.

Results: A total of 2,990 subjects ( $54 \%$ men, mean age 59 years, and mean 28 pack-years) were enrolled, of whom 949 (32\%) proceeded from COPD-6 screening to confirmative spirometry based on the following criteria: $510(54 \%) \mathrm{FEV}_{1} / \mathrm{FEV}_{6}<0.70,382(40 \%) \mathrm{FEV}_{1}<80 \%$ pred, and 57 (6\%) MD decision. Following confirmative spirometry, the 949 individuals were diagnosed as having COPD (51\%), asthma (3\%), and no obstructive lung disease (45\%). COPD was diagnosed in 487 (16\%) of the enrolled subjects in whom confirmative spirometry was performed in $69 \%$ based on $\mathrm{FEV}_{1} / \mathrm{FEV}_{6}<0.7$ and in $29 \%$ based on $\mathrm{FEV}_{1} \leq 80 \%$ pred.

Conclusion: Prescreening with the COPD-6 device showed acceptable specificity for the selection of subjects for diagnostic spirometry and is likely to be a useful alternative to current practice in primary care.

Keywords: early COPD, diagnosis, spirometry, general practice

\section{Introduction}

Previous studies have shown that opportunistic screening in primary care enables early diagnosis of chronic obstructive pulmonary disease (COPD). ${ }^{1,2}$ However, in general, this practice is sparsely implemented. In population-based registry studies, only one third of subjects or less with newly diagnosed COPD had spirometry performed. ${ }^{3-6}$ Furthermore, the requirement of conventional spirometry has been identified as a barrier to early diagnosis. ${ }^{7}$ Delayed diagnosis is a missed opportunity for early secondary prevention, most importantly smoking cessation, which could substantially alter the prognosis. ${ }^{8}$ The demand for screening of an increasing number of subjects has further stressed the need for a feasible procedure.

More than a decade ago, Buffels et al suggested that hand-held spirometers should be made available in primary care. ${ }^{9} \mathrm{FEV}_{6}$ is a measure of forced expiratory volume in
Correspondence: Charlotte Suppli Ulrik Department of Respiratory Medicine, 253, Hvidovre Hospital, DK-2650 Hvidovre, Denmark Email csulrik@dadlnet.dk 
6 seconds as opposed to a full forced vital capacity (FVC) maneuver. Studies have suggested $\mathrm{FEV}_{1} / \mathrm{FEV}_{6}$ measured by spirometry as a valid alternative to $\mathrm{FEV}_{1} / \mathrm{FVC}$ in screening a high-risk population for COPD. ${ }^{10,11}$ A meta-analysis based on 11 studies found a sensitivity of 0.89 (95\% CI $0.83-0.93)$ and specificity of 0.98 (95\% CI $0.95-0.99)$ for $\mathrm{FEV}_{1} / \mathrm{FEV}_{6}$ in recognition of airway obstruction. ${ }^{12}$ Several studies have concluded that hand-held screening devices including the COPD-6 and PiKo-6 device are reliable in screening for airway obstruction and selecting subjects for further diagnostic workup. ${ }^{13-20} \mathrm{~A}$ recent meta-analysis concluded that the accuracy of $\mathrm{FEV}_{1} / \mathrm{FEV}_{6}$ measured by hand-held devices seems to be lower than spirometry, but sufficiently accurate to screen for airway obstruction. ${ }^{21}$

Existing studies of hand-held screening devices have called for studies conducted in a realistic screening setting. This study aimed to investigate whether prescreening with a COPD-6 device facilitates early detection of COPD in a primary care setting.

\section{Materials and methods Materials}

Denmark has $\sim 3,600$ general practitioners (GPs), covering a population of 5.9 million. We aimed to include a representative sample, on a voluntary basis, comprising 180 GPs (corresponding to $5 \%$ of Danish GPs) from all over Denmark. Written information about the study as well as the invitation to participate was distributed to all interested GPs by the sponsor's local representative.

More than $95 \%$ of Danish GPs own a spirometer, which was a requirement to participate in this study. Subjects were eligible for enrollment in the study provided they fulfilled the inclusion criteria based on recommendations from the Danish National Board of Health on opportunistic screening for COPD: age $\geq 35$ years, smoker/ex-smoker or other risk exposures for COPD, at least one respiratory symptom (dyspnea, cough, wheeze, sputum, or recurrent respiratory tract infections $)^{31}$ and had no previous diagnosis of obstructive lung disease or treatment with inhaler medication within the last 12 months. Exclusion criteria were absence of informed consent and inability to perform COPD-6- or spirometry procedure.

\section{Methods}

This multicenter study was conducted from March to December 2015. Based on the spirometry guidelines from the Danish Respiratory Society, ${ }^{32}$ participating GPs were educated in the functions of the COPD-6 (Vitalograph ${ }^{\circledR}$, Buckingham, UK) and spirometry procedures. The COPD-6 test was repeated three times with the highest values recorded. The device automatically detected blows of poor quality (start too slow, coughing, or $<3$ seconds duration of blow). Spirometry was performed with at least three forced expiratory maneuvers (and at least two measurements of $\mathrm{FEV}_{1}$ and $\mathrm{FVC}$, differing by $<5 \%$ ). European Community of Steel and Coal reference values for lung function were used. ${ }^{33}$

The bronchodilator (BD) reversibility tests were performed with $0.4 \mathrm{mg}$ inhaled salbutamol (or equivalent) followed by repeated spirometry 15 minutes later. All procedures were performed in general practice.

Subjects who fulfilled the criteria for inclusion were screened with the COPD-6 device (screening test) and proceeded to diagnostic spirometry with $\mathrm{BD}$ reversibility test, based on three criteria in prioritized order: 1) airway obstruction $\left(\mathrm{FEV}_{1} / \mathrm{FEV}_{6}<0.70\right)$, 2) lung function impairment, that is, $\mathrm{FEV}_{1}<80 \%$ pred, or 3 ) medical doctor's (MD) decision $\left(\mathrm{FEV}_{1} / \mathrm{FEV}_{6}\right.$ close to 0.70 and sustained suspicion of COPD). The prioritized order meant that subjects presenting with both airway obstruction and decreased lung function were categorized into airway obstruction. Based on the findings at the diagnostic spirometry, subjects were categorized as asthma $\left(\Delta \mathrm{FEV}_{1} \geq 0.50 \mathrm{~L}\right)$, COPD (post-BD $\mathrm{FEV}_{1} / \mathrm{FVC}$ ratio $<0.70$ ), or no obstructive lung disease (remaining individuals).

\section{Data handling and analysis}

The aim was to identify at least 500 subjects with COPD and thereby allow for subgroup analyses. Recruitment of 180 GPs was estimated to be sufficient based on, 1) an expected inclusion of at least 30 subjects by each GP, 2) a 15\% prevalence of COPD, and 3 ) an expected dropout rate of $10 \%$.

Data on age, sex, height, body weight, smoking status and/or other risk exposure, pack-years, respiratory symptoms (described above), severity of dyspnea (Medical Research Council scale $),{ }^{34}$ and results of COPD-6 $\left(\mathrm{FEV}_{1}, \mathrm{FEV}_{6}\right)$ and spirometry $\left(\mathrm{FEV}_{1}, \mathrm{FVC}\right.$, post-BD $\mathrm{FEV}_{1}$, and FVC) were entered into a consolidated web-based database. Body mass index (BMI), $\mathrm{FEV}_{1} / \mathrm{FEV}_{6}$, and $\mathrm{FEV}_{1} / \mathrm{FVC}$ were automatically calculated and recorded.

Statistical analyses were performed by using IBM SPSS version 21 (IBM Corporation, Armonk, NY, USA). Analyses were limited to subjects with complete data. Continuous data were tested for normality and paired $t$-test was applied if applicable. For continuous non-normal distributed data, Mann-Whitney $U$ test was used. Categorical data were analyzed by Pearson's chi-squared test. A significance level of 0.05 was set in all analyses. 


\section{Ethics}

The study was endorsed by the Danish College of General Practitioners. According to the European Federation of Pharmaceutical Industries and Associations code and the Danish Association of the Pharmaceutical Industry, the present study was a non-drug, non-interventional study. Approval from the Danish Scientific Ethics Committee and The Danish Medicines Agency was not mandatory, but they were given all relevant study information. Data handling was approved by the Danish Data Protection Agency.

\section{Results}

\section{Characteristics of enrolled subjects}

A total of 149 GPs participated in the study, representing a nationwide sample of both large and small clinics. A total of 2,990 subjects were tested with the COPD-6 screening tool and had complete data (Figure 1). The study population had a mean age of 59 years (range 35-92 years), mean 28 pack-years of smoking, 54\% current smokers, and a COPD-6 mean $\mathrm{FEV}_{1}$ of $2.6 \mathrm{~L}$ (88\%pred) (Table 1).

\section{Prevalence of COPD}

According to the predefined criteria, confirmative spirometry was indicated in 949 cases (32\% of study population) distributed as follows: $510 \mathrm{FEV}_{1} / \mathrm{FEV}_{6}<0.7$ (with or without $\mathrm{FEV}_{1}<80 \%$ pred), $382 \mathrm{FEV}_{1}<80 \%$ pred, and $57 \mathrm{MD}$ decision. Of the 949 subjects tested with diagnostic spirometry, $487(51 \%)$ fulfilled the criteria for COPD (corresponding to $16 \%$ of the study population), 31 (3\%) were categorized as having asthma $\left(\Delta \mathrm{FEV}_{1}>0.5 \mathrm{~L}\right)$, and $431(45 \%)$ as "no obstructive lung disease" (Figure 1).

The prevalence of COPD in subjects selected for diagnostic spirometry by criteria $\mathrm{FEV}_{1} / \mathrm{FEV}_{6}<0.70$ was $352 / 510$ $(69 \%)$ and $110 / 382$ (29\%) based on the criteria $\mathrm{FEV}_{1}<80 \%$ alone (Figures 2 and 3 ). The prevalence of airway obstruction at the COPD- 6 test and at the pre- and post-BD spirometry are given in Table 2.

\section{Criteria for confirmative spirometry}

Applying the single criteria $\mathrm{FEV}_{1} / \mathrm{FEV}_{6}<0.70$ for further diagnostic work-up, $17 \%$ of the screened population would have proceeded to confirmative spirometry. However, compared to the combined criteria used in the current study, a diagnosis of COPD would have been missed in 135 (487-352) subjects, corresponding to $27 \%$ of all subjects diagnosed with COPD in the study. In total, 439 subjects had an $\mathrm{FEV}_{1} / \mathrm{FEV}_{6} \geq 0.70$ at the COPD-6 test, but proceeded to diagnostic spirometry based on $\mathrm{FEV}_{1}<80 \%$ pred (382) or MD decision (57). Of these subjects, 137 had a post-BD $<0.7$ and 135 (31\%) were diagnosed with COPD (Table 2).

For each subject diagnosed with COPD, six COPD-6 tests and two diagnostic spirometry procedures were performed.

\section{Characteristics of subjects screened only with COPD-6 test}

Subjects who did not meet criteria for diagnostic spirometry were in comparison to subjects diagnosed with COPD, significantly younger, had less tobacco exposure, and had an overall

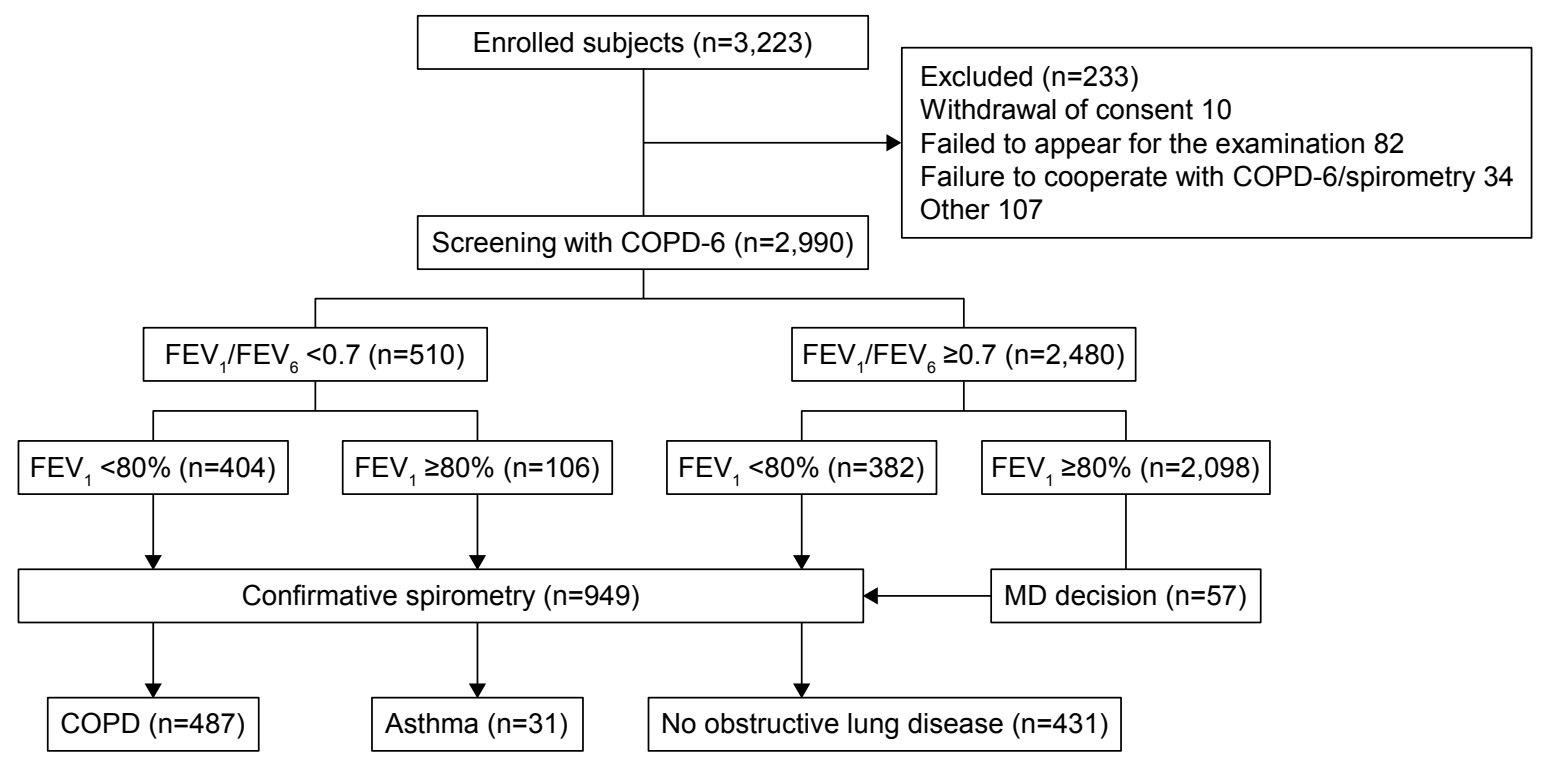

Figure I CONSORT diagram of enrolled subjects.

Notes: The following diagnostic criteria were applied: I) COPD: post-bronchodilator (BD) FEV /FVC $<0.7$ and $<0.5 \mathrm{~L}$ post-BD increase in FEV, 2 ) asthma: post-BD FEV increase $\geq 0.5 \mathrm{~L}$, and 3 ) no obstructive lung disease, that is, not fulfilling any of these criteria.

Abbreviations: COPD, chronic obstructive pulmonary disease; FEV, forced expiratory volume; FVC, forced vital capacity; MD, medical doctor's. 
Table I Baseline characteristics of all enrolled subjects $(n=2,990)$ and classification according to whether participants were only screened with COPD-6 test $(n=2,041)$ or proceeded to confirmative spirometry $(\mathrm{n}=949)^{\mathrm{a}}$

\begin{tabular}{|c|c|c|c|c|}
\hline & $\begin{array}{l}\text { All } \\
(n=2,990)\end{array}$ & $\begin{array}{l}\text { COPD-6 } \\
\text { test only } \\
(n=2,04 I)\end{array}$ & $\begin{array}{l}\text { Confirmative } \\
\text { spirometry } \\
(n=949)\end{array}$ & $\overline{P \text {-value }}{ }^{b}$ \\
\hline Sex, male & I,624 (54\%) & I, II $19(55 \%)$ & 505 (53\%) & NS \\
\hline Age (years) & $59(11.7)$ & $58(11.7)$ & $62(11.0)$ & $<0.001$ \\
\hline BMI $\left(\mathrm{kg} / \mathrm{m}^{2}\right)$ & $28(5.7)$ & $27(5.6)$ & $27(5.9)$ & NS \\
\hline Pack-years & $28(20.0)$ & $25(18.8)$ & $34(22.2)$ & $<0.001$ \\
\hline $\mathrm{FEV}_{1}(\mathrm{~L})$ & $2.6(0.8)$ & $2.9(0.73)$ & $2.0(0.64)$ & \\
\hline FEV , \%pred & $88(18.9)$ & 97 (I2.8) & 69 (15.1) & \\
\hline $\mathrm{FEV}_{6}(\mathrm{~L})$ & $3.4(0.97)$ & $3.7(0.92)$ & $2.9(0.86)$ & $<0.00 \mathrm{I}$ \\
\hline \multicolumn{5}{|l|}{ Symptoms } \\
\hline Cough & I,825 (6I\%) & $\mathrm{I}, 232(60 \%)$ & $593(63 \%)$ & NS \\
\hline Dyspnea & I, I 44 (38\%) & $724(36 \%)$ & 420 (44\%) & $<0.001$ \\
\hline Wheezing & $298(10 \%)$ & $15 \mid(7 \%)$ & 147 (16\%) & $<0.001$ \\
\hline Sputum & $544(18 \%)$ & 327 (16\%) & $217(23 \%)$ & $<0.001$ \\
\hline Recurrent RTI & 112 (4\%) & $65(3 \%)$ & $47(5 \%)$ & 0.018 \\
\hline \multicolumn{5}{|l|}{$M R C^{c}$} \\
\hline I & NA & NA & 176 (I9\%) & \\
\hline 2 & NA & NA & $234(25 \%)$ & \\
\hline 3 & NA & NA & $83(9 \%)$ & \\
\hline 4 & NA & NA & $13(1 \%)$ & \\
\hline 5 & NA & NA & $2(0.43 \%)$ & \\
\hline
\end{tabular}

Notes: aNumerical data presented as mean (SD) and categorical data as $n(\%)$. bSubjects screened only with the COPD- 6 test compared to subjects who proceeded to confirmative spirometry. ${ }^{C}$ Medical Research Council dyspnea scale.

Abbreviations: BMI, body mass index; FEV, forced expiratory volume; MRC, Medical Research Council; NA, not applicable; NS, not significant; RTI, Respiratory tract infections.

lower occurrence of respiratory symptoms with significantly less dyspnea, wheezing, and sputum (Table 1). As expected, the $\mathrm{FEV}_{1}$ was also on average significantly higher; 2.9 versus $2.0 \mathrm{~L}$ ( $97 \%$ vs $69 \%$ predicted), respectively.

\section{Characteristics of subjects with COPD compared to other diagnostic groups}

Compared to subjects categorized as having asthma, subjects with COPD had significantly more pack-years and lower $\mathrm{FEV}_{1}$ and FVC (Table 3). There were no significant differences in symptoms between the two groups, although occurrence of sputum tended to be higher in subjects with COPD.

Subjects with COPD, compared to subjects categorized as having no obstructive lung disease, had significant higher age, lower BMI, and higher number of pack-years and had significantly higher occurrence of dyspnea and sputum (Table 3 ).

In the group with no obstructive lung disease, 215 (50\%) subjects had $\mathrm{FEV}_{1}>80 \%$ pred. For participants finally classified as having no obstructive lung disease, but having a confirmatory spirometry performed based on $\mathrm{FEV}_{1} / \mathrm{FEV}_{6}$ ratio $<0.70,50 \%$ had a $\mathrm{FEV}_{1} / \mathrm{FEV}_{6}$ ratio close to $0.7(\geq 0.65)$. The mean increase in $\mathrm{FEV}_{1}$ at the $\mathrm{BD}$ reversibility test was $0.14 \mathrm{~L}(0.10)$.

Detailed spirometry data according to the three criteria for diagnostic spirometry are presented in Table 4.

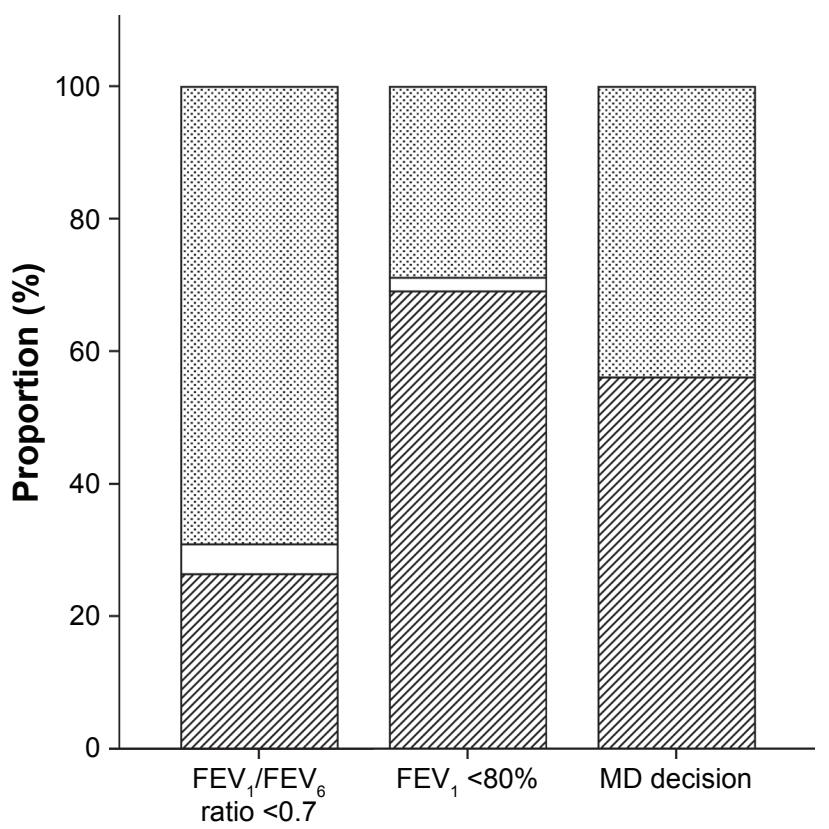

Criteria for spirometry

Diagnosis
卷 COPD $\square$ Asthma $\square$ No obstructive lung disease

Figure 2 Prevalence of final diagnosis, that is, COPD, asthma, or no obstructive lung disease, according to the three different criteria for proceeding to confirmative spirometry.

Notes: Criteria for, I) COPD: post-bronchodilator (BD) FEV /FVC $<0.7$ and $\triangle F E V$, $<0.5 \mathrm{~L}$ at $\mathrm{BD}$ reversibility test; 2 ) asthma: $\Delta \mathrm{FEV}, \geq 0.5 \mathrm{~L}$ at $\mathrm{BD}$ reversibility test; Non-OLD: not fulfilling criteria I) or 2). MD decision: MD decision to perform confirmative spirometry based on suspicion of COPD and an $\mathrm{FEV}_{1} / \mathrm{FVC}$ ratio close to 0.7 . Subjects with both $\mathrm{FEV}_{1} / \mathrm{FEV}_{6}$ ratio $<0.7$ and $\mathrm{FEV},<80 \%$ were counted in the group "FEV $/ \mathrm{FEV}_{6}$ ratio $<0.7$ ".

Abbreviations: FEV, forced expiratory volume; FVC, forced vital capacity; MD, medical doctor's; OLD, obstructive lung disease.

\section{Discussion Main findings}

The study demonstrates that, in a real-life setting, prescreening of high-risk subjects with the COPD-6 device followed by spirometry in selected cases can identify COPD in a high percentage of subjects (16\%). Selection of subjects for confirmative spirometry based on a single criteria $\mathrm{FEV}_{1} / \mathrm{FEV}_{6}<0.70$ was found to be insufficient, and the sensitivity was markedly increased primarily by adding the criterion $\mathrm{FEV}_{1}<80 \%$ pred, and to a lesser extent the criterion MD decision.

Screening with the COPD-6 device showed acceptable specificity for the selection of subjects for diagnostic spirometry.

\section{Interpretation of findings in relation to previously published work}

A COPD prevalence of $16 \%$ was comparable to findings (17\%) reported from a previous study with similar study design, but screening performed only by conventional spirometry. ${ }^{2}$ 
A

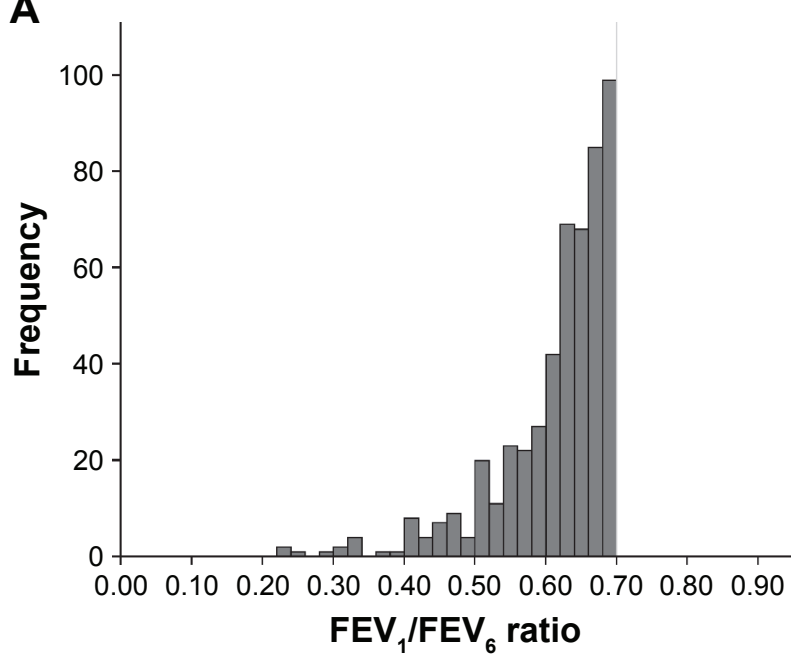

B

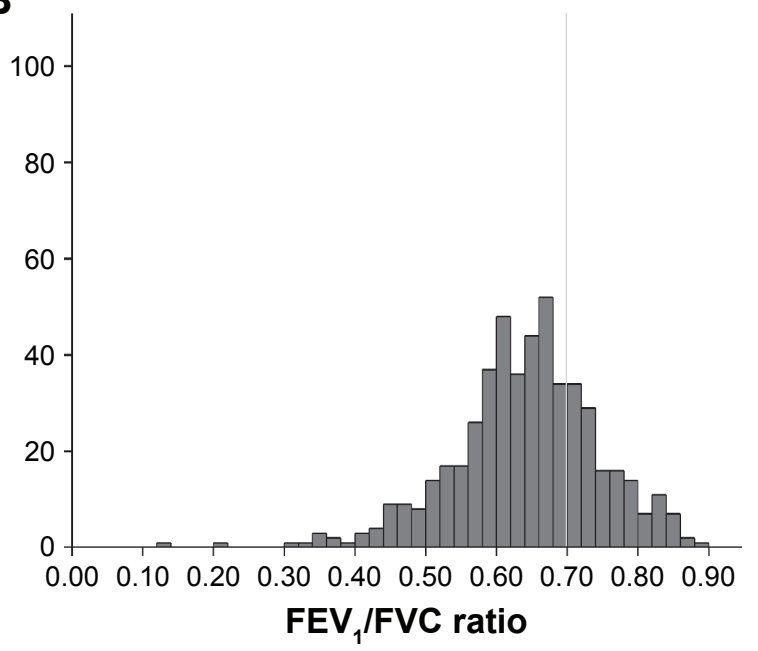

Figure 3 Comparison of the $\mathrm{FEV}_{1} / \mathrm{FEV}$, ratio for subjects with airway obstruction (defined as $\left.\mathrm{FEV}_{1} / \mathrm{FEV}_{6}<0.70\right)$ at the $\mathrm{COPD}-6$ test $(\mathbf{A})(\mathrm{n}=5 \mathrm{I} 0$ ) with the $\mathrm{FEV} / \mathrm{FVC}$ ratio at the subsequent post-BD spirometry (B).

Abbreviations: $\mathrm{BD}$, bronchodilator; FEV, forced expiratory volume; FVC, forced vital capacity.

A post hoc analysis of data from that study showed that six screening spirometry and 1.4 confirmative spirometry procedures had to be performed per diagnosed subject with COPD. ${ }^{22}$ Compared to the current study, the COPD- 6 device as expected did not reduce the total number of procedures (screening tests plus diagnostic tests), but worked as a replacement for the conventional spirometry screening test.

Six other GP multicenter studies of screening with a COPD-6 device for early detection of COPD were identified. In accordance with the other studies, the vast majority of subjects in the current study had mild to moderate disease. For subjects with available data also on exacerbations, twothirds belonged to GOLD group A.

One study (Miravitlles et al) had to be disregarded as it is published only in Spanish. ${ }^{18}$ The two studies by Muller et al and Represas-Represas et al only included subjects if they had respiratory symptoms and exposure to tobacco smoke. ${ }^{14,19}$

Table 2 Prevalence of airway obstruction $\left(\mathrm{FEV}_{1} / \mathrm{FVC}<0.70\right)$ at the COPD-6 test and at pre- and post-bronchodilator spirometry according to criteria for performing confirmative spirometry

\begin{tabular}{|c|c|c|c|}
\hline Criteria for spirometry & COPD-6 & $\begin{array}{l}\text { Spirometry } \\
\text { pre-BD }\end{array}$ & $\begin{array}{l}\text { Spirometry } \\
\text { post-BD }\end{array}$ \\
\hline (A) $\mathrm{FEV}_{1} / \mathrm{FEV}_{6}<0.7(\mathrm{n}=5 \mathrm{IO})$ & 510 & $402(79 \%)$ & $368(72 \%)$ \\
\hline (B) $\mathrm{FEV}_{1}<80 \%$ pred $^{\mathrm{c}}(\mathrm{n}=382)$ & NA & $139(36 \%)$ & II 2 (29\%) \\
\hline (C) $M D^{d}(n=57)$ & NA & 31 (54\%) & $25(44 \%)$ \\
\hline All $(n=949)$ & 510 & $572(60 \%)$ & 505 (53\%) \\
\hline
\end{tabular}

Notes: ${ }^{\text {aPre-BD }}$ values. ${ }^{\mathrm{b}}$ Post-BD values. cSubjects with both $\mathrm{FEV} / \mathrm{FEV},<0.7$ and $\mathrm{FEV}_{1}<80 \%$ pred included in $\mathrm{A}$. $\mathrm{dMD}$ decision (continued clinical suspicion of COPD and $\mathrm{FEV}_{1} / \mathrm{FEV}_{6}$ close to 0.70 ).

Abbreviations: BD, bronchodilator; FEV, forced expiratory volume; FVC, forced vital capacity; MD, medical doctor's; NA, not applicable.
Muller et $\mathrm{al}^{19}$ included 17,856 subjects and found airway obstruction $\left(\mathrm{FEV}_{1} / \mathrm{FEV}_{6}<0.7\right)$ in $17 \%$ of the subjects, and interestingly, a diagnosis of COPD was independently suspected by the MD three times more than indicated by the COPD-6 device. No data from confirmative spirometry was included in the study, thus, direct comparison with our study is not possible. A recent smaller study by Represas-Represas et al included a mixed cohort of 362 subjects from general practice, emergency services, and community pharmacies and found a COPD prevalence of $40 \%$ in the general practice cohort ( $\mathrm{n}=167) .{ }^{23}$ The high prevalence of COPD most likely reflects a much higher tobacco exposure compared to the current study (75\% active smokers, mean pack-years 39 ). An optimal cutoff of $\mathrm{FEV}_{1} / \mathrm{FEV}_{6}$ of 0.8 was proposed corresponding to a sensitivity of $92 \%$ and specificity of $53 \%$.

Llordes et al included 407 subjects and found a COPD prevalence of $26 \%{ }^{24}$ The study was similar to our study with regard to smoking exposure and age, and no obvious explanation for the difference in prevalence can be identified based on the available information. Different screening strategies including screening questionnaires and the COPD-6 device were tested, and the latter was found significantly superior with an $\mathrm{FEV}_{1} / \mathrm{FEV}_{6}$ cutoff of 0.78 (sensitivity $88 \%$ and specificity $72 \%$ ).

Another multicenter study by Thorn et al including 305 subjects found a COPD prevalence of $25 \% .{ }^{17}$ The higher prevalence of COPD in that study was likely due to inclusion criteria with a minimum smoking exposure of $\geq 15$ packyears. An $\mathrm{FEV}_{1} / \mathrm{FEV}_{6}$ cutoff of 0.73 was suggested, which corresponds to a sensitivity and specificity of $79 \%$ and $80 \%$, 
Table 3 Characteristics of subjects diagnosed with COPD compared to subjects diagnosed with asthma and no obstructive lung disease (no OLD) $)^{\mathrm{a}, \mathrm{b}}$

\begin{tabular}{|c|c|c|c|c|c|}
\hline & $\begin{array}{l}\text { COPD } \\
(n=487)\end{array}$ & $\begin{array}{l}\text { Asthma } \\
(\mathrm{n}=3 \mathrm{I})\end{array}$ & $\begin{array}{l}P \text {-value } \\
\text { (COPD vs asthma) }\end{array}$ & $\begin{array}{l}\text { No OLD } \\
(n=43 I)\end{array}$ & $\begin{array}{l}P \text {-value } \\
\text { (COPD vs no OLD) }\end{array}$ \\
\hline Sex, male & 259 (53\%) & 22 (7I\%) & 0.054 & 224 (52\%) & 0.714 \\
\hline Age (years) & $64(10.5)$ & $63(12.5)$ & 0.433 & $6 I(1 \mathrm{I} .2)$ & $<0.001$ \\
\hline BMI $\left(\mathrm{kg} / \mathrm{m}^{2}\right)$ & $26(5.1)$ & $28(5.8)$ & 0.061 & $28(6.5)$ & $<0.00 \mathrm{I}$ \\
\hline Pack-years & $37(2 \mid .4)$ & $27(17.6)$ & 0.005 & $30(22.8)$ & $<0.00 \mathrm{I}$ \\
\hline $\mathrm{FEV}_{1}(\mathrm{~L})$ & $2.0(0.65)$ & $3.0(0.92)$ & $<0.001$ & $2.4(0.73)$ & $<0.00 \mathrm{I}$ \\
\hline FEV, \%pred & $72(16.9)$ & $87(21.1)$ & $<0.001$ & $80(14.8)$ & $<0.00 \mathrm{I}$ \\
\hline FVC (L) & $3.3(0.98)$ & $4.5(1.3)$ & $<0.001$ & $3.1(0.93)$ & $<0.00 \mathrm{I}$ \\
\hline $\mathrm{FEV}_{1} / \mathrm{FVC}$ & $0.6 \mathrm{I}(0.08)$ & $0.69(0.14)$ & 0.005 & $0.77(0.06)$ & $<0.001$ \\
\hline$\Delta \mathrm{FEV}_{1}(\mathrm{~L})$ & $0.08(0.18)$ & $0.74(0.30)$ & $<0.001$ & $0.05(0.18)$ & $<0.00 \mathrm{I}$ \\
\hline \multicolumn{6}{|l|}{ Symptoms } \\
\hline Cough & $309(63 \%)$ & I 8 (58\%) & 0.547 & 266 (62\%) & 0.588 \\
\hline Dyspnea & $242(50 \%)$ & 15 (48\%) & 0.888 & 163 (38\%) & $<0.00 \mathrm{I}$ \\
\hline Wheezing & 77 (16\%) & $6(19 \%)$ & 0.602 & 64 (15\%) & 0.687 \\
\hline Sputum & 129 (27\%) & $6(19 \%)$ & 0.380 & 82 (19\%) & 0.007 \\
\hline Recurrent RTI & $22(5 \%)$ & I (3\%) & 0.735 & $24(6 \%)$ & 0.466 \\
\hline \multicolumn{6}{|l|}{$M R C^{c}$} \\
\hline 1 & 142 (34\%) & $8(50 \%)$ & & $26(6 \%)$ & \\
\hline 2 & 194 (47\%) & 7 (44\%) & & $33(8 \%)$ & \\
\hline 3 & 64 (15\%) & 7 (44\%) & & $18(4 \%)$ & \\
\hline 4 & $13(3 \%)$ & $0(0 \%)$ & & $0(0 \%)$ & \\
\hline 5 & $2(0.5 \%)$ & $0(0 \%)$ & & $0(0 \%)$ & \\
\hline \multicolumn{6}{|l|}{ GOLD stage ${ }^{d}$} \\
\hline 1 & 152 (31\%) & & & & \\
\hline II & $294(60 \%)$ & & & & \\
\hline III & $38(8 \%)$ & & & & \\
\hline IV & $3(1 \%)$ & & & & \\
\hline \multicolumn{6}{|l|}{ GOLD group ${ }^{\mathrm{d}, \mathrm{e}}$} \\
\hline A & $303(62 \%)$ & & & & \\
\hline B & 57 (I2\%) & & & & \\
\hline $\mathrm{C}$ & $33(7 \%)$ & & & & \\
\hline D & 22 (5\%) & & & & \\
\hline
\end{tabular}

Notes: ${ }^{\mathrm{a}}$ ) Criteria for COPD: post-BD FEV $/ \mathrm{FVC}<0.7$ and $\triangle \mathrm{FEV},<0.5 \mathrm{~L}$ at BD reversibility test; 2 ) Asthma: $\triangle \mathrm{FEV}, \geq 0.5 \mathrm{~L}$ at $\mathrm{BD}$ reversibility test; No OLD: not fulfilling criteria I) or 2). ${ }^{b}$ Numerical data presented as mean (SD) and categorical data as $n$ (\%). CMedical Research Council dyspnea scale. ${ }^{\circ}$ Global Initiative for Chronic Obstructive Lung Disease. Global Strategy for Diagnosis, Management and Prevention of COPD; 2016 . In 72 (15\%) cases, the number of exacerbations was not recorded, thus the GOLD group could not be specified.

Abbreviations: BD, bronchodilator; BMI, body mass index; FEV, forced expiratory volume; FVC, forced vital capacity; MRC, Medical Research Council; OLD, obstructive lung disease; RTI, Respiratory tract infections.

respectively and at a cutoff of 0.7 , the numbers were $53 \%$ and $90 \%$, respectively. They concluded that the COPD-6 device may reduce the number of unnecessary spirometry tests, and the results were similar to two other studies, in which an almost similar device (Piko-6, measuring FEV $/$ $\mathrm{FEV}_{6}$ ) was validated for the prediction of COPD. ${ }^{15,16}$ None of the described studies accounted for the occurrence of asthma in the cohort. The present study also differed in the use of a combined criteria for confirmatory spirometry including both $\mathrm{FEV}_{1} / \mathrm{FEV}_{6}$ ratio $<0.7$ and $\mathrm{FEV}_{1}<80 \%$ pred.

While general screening of all individuals with smoking exposure is not recommended, US Preventive Services
Task Force (USPSTF) recently recommended screening of all exposed individuals with respiratory symptoms, which is in concordance with the latest recommendations from GOLD. ${ }^{25,26}$

Studies of spirometry and the correlation between $\mathrm{FEV}_{1} /$ $\mathrm{FEV}_{6}$ ratio and $\mathrm{FEV}_{1} / \mathrm{FVC}$ have suggested that the cutoff for airway obstruction when using $\mathrm{FEV}_{6}$ should be set at a significantly higher level. ${ }^{11,12,27,28}$ Accordingly studies of the COPD-6 device show that the best correlation to an $\mathrm{FEV}_{1} /$ $\mathrm{FVC}$ ratio of 0.7 is an $\mathrm{FEV}_{1} / \mathrm{FEV}_{6}$ ratio of $0.73-0.75 . .^{14,17,18}$ However, our COPD-6 device was technically limited to a cutoff value for airway obstruction of 0.7 . Thus, the combined 
Table 4 Spirometry data grouped by selection criteria for confirmative spirometry

\begin{tabular}{|c|c|c|c|}
\hline & $\begin{array}{l}\text { Criteria } A^{a} \\
(n=5 \mid 0)\end{array}$ & $\begin{array}{l}\text { Criteria } B^{b} \\
(n=382)\end{array}$ & $\begin{array}{l}\text { Criteria C } \\
(n=57)\end{array}$ \\
\hline \multicolumn{4}{|l|}{ COPD-6 } \\
\hline $\mathrm{FEV}_{1}(\mathrm{~L})$ & $1.9(0.65)$ & $2.06(0.52)$ & $2.72(0.63)$ \\
\hline $\mathrm{FEV}_{1}<80 \%$ pred & $65 \%(17.6)$ & $70 \%(7.5)$ & $91 \%(8.4)$ \\
\hline $\mathrm{FEV}_{6}(\mathrm{~L})$ & $3.0(0.93)$ & $2.68(0.67)$ & $3.57(0.87)$ \\
\hline $\mathrm{FEV}_{1} / \mathrm{FEV}_{6}$ ratio & $0.62(0.08)$ & $0.77(0.05)$ & $0.77(0.06)$ \\
\hline \multicolumn{4}{|l|}{ Confirmative spirometry ${ }^{d}$} \\
\hline $\mathrm{FEV}_{1}(\mathrm{~L})$ & $2.18(0.76)$ & $2.24(0.64)$ & $2.73(0.68)$ \\
\hline $\mathrm{FEV}_{1}<80 \%$ pred & $75 \%(19.2)$ & $77 \%(13.4)$ & $88 \%(15.4)$ \\
\hline FVC (L) & $3.39(1.10)$ & $3.06(0.85)$ & $3.81(0.94)$ \\
\hline $\mathrm{FEV} / \mathrm{FVC}$ ratio & $0.64(0.11)$ & $0.73(0.08)$ & $0.72(0.07)$ \\
\hline$\Delta \mathrm{FEV}_{1}(\mathrm{~L})$ & $0.11(0.31)$ & $0.07(0.17)$ & $0.03(0.15)$ \\
\hline$\Delta \mathrm{FEV}_{\mathrm{L}}>0.2 \mathrm{~L}$ and $\mathrm{I} 2 \%$ & $88(17 \%)$ & $40(10.5 \%)$ & I (I.8\%) \\
\hline
\end{tabular}

Notes: ${ }^{\mathrm{a} F E V} / \mathrm{FEV}_{6}<0.7$. ${ }^{\mathrm{b} F E V_{1}}<80 \%$ predicted. Subjects with both $\mathrm{FEV}_{1} / \mathrm{FEV}_{6}<0.7$ and $\mathrm{FEV},<80 \%$ predicted are counted as A. Medical Doctor's decision (continued suspicion of $\mathrm{COPD}$ and $\left.\mathrm{FEV}_{1} / \mathrm{FEV}_{6} \sim 0.7\right)$. ${ }^{\text {dPost-bronchodilator values. }}$ Abbreviations: FEV, forced expiratory volume; FVC, forced vital capacity.

criterion for diagnostic spirometry was decided in order to compensate for the risk of insufficient sensitivity. Our results confirmed the issue by showing that although 439 diagnostic spirometry procedures could be spared, $27 \%$ of the subjects with COPD in the study would have been missed by the single criterion diagnostic algorithm. Accordingly, of the 439 subjects with a normal COPD- 6 test who proceeded to diagnostic spirometry based on the other two criteria, $31 \%$ was diagnosed with COPD.

GOLD recommends a simple and operational definition of airway obstruction in primary care (post-BD FEV $\mathrm{F}_{1}$ $\mathrm{FVC}<0.70$ ) and points out the risk of over-diagnosis in the elder- and under-diagnosis of the younger population. ${ }^{26}$ The MD decision criterion, by which the GP was allowed to perform diagnostic spirometry in subjects with $\mathrm{FEV}_{1} / \mathrm{FEV}_{6}$ close to 0.7 , was in accordance with GOLD recommendations.

Significant BD reversibility is not uncommon in COPD. ${ }^{29}$ In the current study, a strict definition of asthma $\left(\mathrm{FEV}_{1}\right.$ change $>0.5 \mathrm{~L}$ ) was chosen not only to exclude this group of subjects but also because some of these participants may have asthma-COPD overlap. ${ }^{30}$ As a result, the group of subjects diagnosed as having asthma was small $(n=31)$. As expected, compared to the asthma group, the COPD group had significantly higher tobacco exposure, lower $\mathrm{FEV}_{1}$, and a trend toward a higher occurrence of sputum.

Subjects in the category "no obstructive lung disease" were overall a little younger with less tobacco exposure and less dyspnea and sputum. Half the subjects had normal FEV at confirmative spirometry and the majority of the group were overweight or obese, most likely representing subjects without clinically significant lung disease, although some individuals may have asthma despite an only moderate, or no, response to a BD.

\section{Strengths and limitations of this study}

The number of GPs enrolled was less than the planned 180 GPs. Nevertheless, the aim of identifying 500 subjects with COPD was largely met ( $\mathrm{n}=487)$. An acceptable number of potentially eligible subjects $(n=233)$ were excluded for various reasons; further details are given in Figure 1. The study sample was large and included 149 GPs with a wide geographical representation from across the nation including large and small GP clinics. Thus, the results are very likely to be representative for GP clinics in general, at least in Denmark. The study group had a wide representation of age and an even distribution of sex. A large proportion (more than half) of the study population were current smokers. With regard to the subjects who did not proceed to diagnostic spirometry, the characteristics seem to justify exclusion: younger, less tobacco exposure, less symptoms, and a mean $\mathrm{FEV}_{1}$ predicted of $97 \%$. Furthermore, in order to improve the quality of the COPD- 6 and spirometry test, experienced personnel visited the clinics and gave training in performing the procedures.

It limits the study that confirmative spirometry was not conducted on all included patients. Thus, the extent of false-negative COPD-6 procedures could not be examined. However, the number of COPD patients found in the study equals what was expected based on a prior spirometry screening study also in Danish primary care, which indicates few false negatives. ${ }^{22}$ Furthermore, the possibility of a false-negative COPD-6 test and missed COPD diagnosis was limited to subjects with mild disease $\left(\mathrm{FEV}_{1}>80 \%\right)$. Conducting both COPD-6 and conventional spirometry on all included patients would have conflicted with the secondary aim of the study to test whether the GPs found the COPD-6 device feasible in everyday work. However, by leaving it out, a direct comparison of COPD-6 and conventional spirometry in COPD screening could not be done.

\section{Implications for future research, policy, and practice}

As the COPD-6 screening test seems to be less time consuming and easier to perform, our results support the procedure as a favorable alternative which can facilitate the detection of COPD in primary care. The important aspect of the 
participating GPs' experience with the COPD-6 screening tool is, therefore, currently being studied.

With focus on the COPD-6 device as a possible quick and handy screening tool, quality of the procedure must not be neglected. Standardization of the procedure is important to ensure reliability and reproducibility, as done in the present study.

\section{Conclusion}

The COPD-6 device seems to be a feasible alternative to conventional spirometry for early detection of COPD in general practice. Qualitative evaluation is necessary to fully assess the potential of the device in overcoming current barriers in screening for COPD in high-risk populations. Consensus on the exact criteria for performing confirmative spirometry including the optimal cutoff value for $\mathrm{FEV}_{1} / \mathrm{FEV}_{6}$ ratio is needed.

\section{Acknowledgments}

The authors wish to thank all participating GPs, their staff, and, not least of all, participating individuals.

The study was financially funded by BoehringerIngelheim, Denmark. The financial support provided by Boehringer-Ingelheim had no influence on the content of the manuscript. None of the authors received any compensation related to the development of this manuscript.

\section{Author contributions}

All authors contributed toward data analysis, drafting and critically revising the paper and agree to be accountable for all aspects of the work.

\section{Disclosure}

All the authors are members of the TOPTrack steering committee. The authors report no other conflicts of interest in this work.

\section{References}

1. Yawn BP, Duvall K, Peabody J, et al. The impact of screening tools on diagnosis of chronic obstructive pulmonary disease in primary care. $\mathrm{Am}$ J Prev Med. 2014;47:563-575.

2. Lokke A, Ulrik CS, Dahl R, et al. Detection of previously undiagnosed cases of COPD in a high-risk population identified in general practice. COPD. 2012;9:458-465.

3. Joo MJ, Lee TA, Weiss KB. Geographic variation of spirometry use in newly diagnosed COPD. Chest. 2008;134:38-45.

4. Lee TA, Bartle B, Weiss KB. Spirometry use in clinical practice following diagnosis of COPD. Chest. 2006;129:1509-1515.

5. Han MK, Kim MG, Mardon R, et al. Spirometry utilization for COPD: how do we measure up? Chest. 2007;132:403-409.

6. Wise J. COPD diagnosis must improve, says report by Royal College of Physicians. BMJ. 2016;355:i6184.
7. Haroon S, Jordan RE, Fitzmaurice DA, Adab P. Case finding for COPD in primary care: a qualitative study of the views of health professionals. Int J Chron Obstruct Pulmon Dis. 2015;10:1711-1718.

8. Jones RC, Price D, Ryan D, et al. Opportunities to diagnose chronic obstructive pulmonary disease in routine care in the UK: a retrospective study of a clinical cohort. Lancet Respir Med. 2014;2: 267-276.

9. Buffels J, Degryse J, Heyrman J, Decramer M; DIDASCO Study. Office spirometry significantly improves early detection of COPD in general practice: the DIDASCO Study. Chest. 2004;125:1394-1399.

10. Swanney MP, Jensen RL, Crichton DA, Beckert LE, Cardno LA, Crapo RO. FEV(6) is an acceptable surrogate for FVC in the spirometric diagnosis of airway obstruction and restriction. Am J Respir Crit Care Med. 2000;162:917-919.

11. Vandevoorde J, Verbanck S, Schuermans D, Kartounian J, Vincken W. FEV1/FEV6 and FEV6 as an alternative for FEV1/FVC and FVC in the spirometric detection of airway obstruction and restriction. Chest. 2005;127:1560-1564.

12. Jing JY, Huang TC, Cui W, Xu F, Shen HH. Should FEV1/FEV6 replace FEV1/FVC ratio to detect airway obstruction? A metaanalysis. Chest. 2009;135:991-998.

13. Duong-Quy S, Hua-Huy T, Mai-Huu-Thanh B, et al. Detection precoce de la bronchopneumopathie chronique obstructive post-tabagique au Viet Nam. [Early detection of smoking related chronic obstructive pulmonary disease in Vietnam]. Rev Mal Respir. 2009;26:267-274. French.

14. Represas Represas C, Botana Rial M, Leiro Fernandez V, Gonzalez Silva AI, del Campo Perez V, Fernandez-Villar A. Validacion del dispositivo portatil COPD-6 para la deteccion de patologias obstructivas de la via aerea. [Assessment of the portable COPD-6 device for detecting obstructive airway diseases]. Arch Bronconeumol. 2010;46:426-432. Spanish.

15. Sichletidis L, Spyratos D, Papaioannou M, et al. A combination of the IPAG questionnaire and PiKo-6(R) flow meter is a valuable screening tool for COPD in the primary care setting. Prim Care Respir J. 2011;20: 184-189, $181 \mathrm{p}$ following 189.

16. Frith P, Crockett A, Beilby J, et al. Simplified COPD screening: validation of the PiKo-6(R) in primary care. Prim Care Respir J. 2011;20: 190-198, $192 \mathrm{p}$ following 198.

17. Thorn J, Tilling B, Lisspers K, Jorgensen L, Stenling A, Stratelis G. Improved prediction of COPD in at-risk patients using lung function pre-screening in primary care: a real-life study and cost-effectiveness analysis. Prim Care Respir J. 2012;21:159-166.

18. Miravitlles M, Llor C, Calvo E, Diaz S, Diaz-Cuervo H, GonzalezRojas N. del FEV1/FEV6 para el diagnóstico de enfermedad pulmonar obstructiva crónica. [Validation of the Spanish version of the Chronic Obstructive Pulmonary Disease-Population Screener (COPD-PS). Its usefulness and that of FEV(1)/FEV(6) for the diagnosis of COPD]. Med Clin (Barc). 2012;139:522-530. Spanish.

19. Muller M, Kogler H, Glaab T, Welte T. COPD-Screening in der hausarztlichen Praxis mit einem Lungenfunktions-Schnellmessgerat. [Use of a lung function screening device for identifying patients at risk for COPD in general practice]. Pneumologie. 2012;66:645-649. German.

20. van den Bemt L, Wouters BC, Grootens J, Denis J, Poels PJ, Schermer TR. Diagnostic accuracy of pre-bronchodilator FEV1/FEV6 from microspirometry to detect airflow obstruction in primary care: a randomised crosssectional study. NPJ Prim Care Respir Med. 2014;24:14033.

21. Haroon S, Jordan R, Takwoingi Y, Adab P. Diagnostic accuracy of screening tests for COPD: a systematic review and meta-analysis. BMJ Open. 2015;5:e008133.

22. Kjeldgaard P, Dahl R, Lokke A, Ulrik CS. Detection of COPD in a high-risk population: should the diagnostic work-up include bronchodilator reversibility testing? Int J Chron Obstruct Pulmon Dis. 2015;10:407-414.

23. Represas-Represas C, Fernandez-Villar A, Ruano-Ravina A, PriegueCarrera A, Botana-Rial M; study group of "Validity of COPD-6 in non-specialized healthcare settings." Screening for chronic obstructive pulmonary disease: validity and reliability of a portable device in nonspecialized healthcare settings. PLoS One. 2016;11:e0145571. 
24. Llordes M, Zurdo E, Jaen A, Vazquez I, Pastrana L, Miravitlles M. Which is the best screening strategy for COPD among smokers in primary care? COPD. 2016;14(1):1-9.

25. Guirguis-Blake JM, Senger CA, Webber EM, Mularski RA, Whitlock EP. Screening for chronic obstructive pulmonary disease: evidence report and systematic review for the US Preventive Services Task Force. JAMA. 2016;315:1378-1393.

26. Global Initiative for Chronic Obstructive Lung Disease. Global Strategy for Diagnosis, Management and Prevention of COPD; 2017. Available from: www.goldcopd.com. Accessed January 05, 2017.

27. Rosa FW, Perez-Padilla R, Camelier A, et al. Efficacy of the FEV1/ FEV6 ratio compared to the FEV1/FVC ratio for the diagnosis of airway obstruction in subjects aged 40 years or over. Braz J Med Biol Res. 2007;40:1615-1621.

28. Vandevoorde J, Verbanck S, Schuermans D, Kartounian J, Vincken W. Obstructive and restrictive spirometric patterns: fixed cut-offs for FEV1/ FEV6 and FEV6. Eur Respir J. 2006;27:378-383.

29. Albert P, Agusti A, Edwards L, et al. Bronchodilator responsiveness as a phenotypic characteristic of established chronic obstructive pulmonary disease. Thorax. 2012;67:701-708.

30. Nielsen M, Barnes CB, Ulrik CS. Clinical characteristics of the asthmaCOPD overlap syndrome - a systematic review. Int J Chron Obstruct Pulmon Dis. 2015;10:1443-1454.
31. KOL: Anbefalinger for tidlig opsporing, opfølgning, behandling og rehabilitering (COPD: Recommendations for early detection, monitoring, treatment and rehabilitation). Danish National Board of Health; 2017. Available from: https:/www.sst.dk/da/udgivelser/2017/ /media/ 8365DCEC9BB240A0BD6387A81CBDBB49.ashx. Accessed June 1, 2017.

32. Madsen F, Maltbæk N, Mortensen J, Pedersen OF. Lungefunktionsstandard; Spirometri og peakflow Lungevolumen Lungediffusionskapacitet. [Standard for lung function; Spirometry and peak flow Lung volume Lung diffusion capacity]. Danish Society of Respiratory Medicine; 2007. Available from: https://www.lungemedicin.dk/fagligt/ klaringsrapporter/5-lfu-standard/file.html. Accessed November 28, 2016. Danish.

33. Quanjer PH, Tammeling GJ, Cotes JE, et al. Symbols, abbreviations and units. Working Party Standardization of Lung Function Tests, European Community for Steel and Coal. Eur Respir J Suppl. 1993;16:85-100.

34. Bestall JC, Paul EA, Garrod R, Garnham R, Jones PW, Wedzicha JA. Usefulness of the Medical Research Council (MRC) dyspnoea scale as a measure of disability in patients with chronic obstructive pulmonary disease. Thorax. 1999;54:581-586.
International Journal of COPD

\section{Publish your work in this journal}

The International Journal of COPD is an international, peer-reviewed journal of therapeutics and pharmacology focusing on concise rapid reporting of clinical studies and reviews in COPD. Special focus is given to the pathophysiological processes underlying the disease, intervention programs, patient focused education, and self management protocols.

\section{Dovepress}

This journal is indexed on PubMed Central, MedLine and CAS. The manuscript management system is completely online and includes a very quick and fair peer-review system, which is all easy to use. Visit http://www.dovepress.com/testimonials.php to read real quotes from published authors.

Submit your manuscript here: http://www.dovepress.com/international-journal-of-chronic-obstructive-pulmonary-disease-journal 